\title{
Técnicas del juicio oral en Colombia: retos y desafíos desde el aula de clase
}

Abogado y especialista en Derecho Penal (Universidad Nacional de Colombia). Tutor de los equipos de estudiantes de la USCO que participaron en el I Concurso Universitario de Oralidad Procesal (Universidad Santo Tomás de BogotáNov. 2003). Docente de la Universidad Surcolombiana.

\section{Presentación}

A partir del primero de enero de 2005 y de forma gradual hasta el 31 de diciembre de 2008 entrará en vigencia un sistema penal de juzgamiento que varía radicalmente el hoy existente, al punto que "...el grueso de los abogados quedará absolutamente derogado en sus conocimientos...: ${ }^{\mathrm{I}}$. Sin embargo, no es el mero tránsito legislativo el que explica tan preocupante pronóstico. Son laś dificultades propias de pasar de un sistema prevalentemente escritural a uno fundado en la oralidad de las actuaciones. Es por ello, que los expertos y promotores han coincidido en señalar que se exige una transformación cultural que comprometa a todos los agentes participes del sistema (jueces, fiscales, abogados litigantes, Ministerio Público, policía judicial etc.). Esa futura realidad no le debe ser ajena desde el presente a la Universidad Colombiana.

El presente documento, invita a la academia nacional y especialmente regional a reconocer los retos y desafíos que la implementación del nuevo
Jesús Ángel Bobadilla Moreno sistema exige y que nos permita elaborar propuestas para el abordaje desde el aula de clase de la enseñanza práctica de las técnicas de juicio oral. He de reconocer que la tarea ya ha sido iniciada por un buen número de instituciones universitarias públicas y privadas que hacen parte del "programa para una cultura de la oralidad desde la Universidad colombiana" desarrollado al interior de la Comisión Interinstitucional para el impulso de la oralidad en el proceso penal y que ha contado con el auspicio, impulso y financiación del Programa de Fortalecimiento y Acceso a la Justicia de Checchi and Company Consulting Colombia y la Agencia de lo Estados Unidos para el Desarrollo Internacional USAID.

Para aterrizar en el tema propuesto, igualmente resulta importante describir brevemente cuáles son los más destacados principios y características que sostendrán y delinearán el futuro sistema, cómo queda diseñada la estructura de la actuación penal y una aproximación a las técnicas del juicio oral que permitan

I Jaramillo, Díaz. Juan Guillermo. «Proyecto de Sistema Procesal Penal Tipo Acusatorion. Librería Jurídica Sánchez R. Ltda. $1^{\text {a }}$ edición 2004. Pág. 9. 
su adecuada preparación a través de la elaboración de la teoría del caso.

I. Principios y características del sistema acusatorio

Los principios y características que orientarán las actuaciones penales devienen de la propia Constitución Política (reformada por el acto legislativo 03 de 2002) y los estándares internacionales que han sido reconocidos por los organismos con jurisdiccional internacional, los altos tribunales de justicia nacional y recientemente han sido recopilados en el Estatuto de Roma que creó la Corte Penal Internacional.

Me referiré solamente a aquellos que resultan novedosos o que adquieren mayor apropiación y realización en el sistema propuesto.

\section{$>$ Principlo de publicidad}

Siempre se ha sostenido que la justicia secreta propicia la corrupción, la arbitrariedad y el atropello. El proceso penal que se concreta en el juicio debe ser público, de frente no solo a las partes y los usuarios sino a la comunidad jurídica y a la sociedad misma, que controlarán las decisiones que tomen sus jueces para verificar la razonabilidad y consistencia de las mismas, fomentando con ello la seguridad jurídica. En síntesis, la publicidad facilita la transparencia de la justicia penal.

Principio de separación de funciones de acusación y juzgamiento

El Acto Legislativo 03 de 2002 acierta al eliminar la mayoría (hubiéramos preferido que fueran todas) de funciones jurisdiscentes de la Fiscalía pasando a ser requirente ante los jueces que ejerzan la función de control de garantías de aquellas decisiones (salvo la excepciones que se colaron en la reforma) que afecten derechos y garantías fundamentales del ciudadano.

Significa lo anterior, que la Fiscalía se concentra en investigar (asegurando la prueba) y acusar ante los jueces a los indiciados como infractores de la ley penal. Los jueces de conocimiento, por su parte, dirigirán el juicio de forma imparcial y descontaminada aprehendiendo directamente el debate probatorio y fallando en derecho.

\section{$>$ Principio de igualdad de las partes}

Consagrada constitucionalmente la separación de funciones deviene de contera el respeto por la igualdad de las partes. El Estado y el juez deben garantizar la real vigencia del equilibrio entre las partes (acusador y defensa).

Por lo anterior, en un sistema adversarial como el que se propone le corresponde al Estado dotar a la defensa pública de las herramientas e infraestructura técnica y científica adecuada que permita enfrentar en igualdad de armas a una poderosa institución (la Fiscalía) que dedicará todos sus esfuerzos y hombres a "investigar, investigar e investigar" como lo sostuvo su titular, parodiando a nuestro presidente, al momento de anunciar la reforma constitucional que se abría camino. 
$>$ Principio de oralidad

"Para algunos un principio consustancial al sistema acusatorio, para otros ${ }^{2}$ un mero instrumento del sistema por cuanto no es una finalidad en sí misma, la oralidad facilita la realización de otros principios (inmediación, publicidad, contradicción, etc).

Consiste en que las peticiones se formularán por las partes ante el juez en audiencia y con citación de la contraparte, siendo allí mismo la oportunidad para resolverse. En principio, no se permitirá la introducción de diligencias (actas, dictámenes) sino que corresponde recibir la declaración del órgano de prueba (investigador, perito) a menos que las partes de común acuerdo estipulen su admisión.

Quiera Dios que no se quede en el papel (que contrasentido) la disposición del constituyente ordinario que exige el debate oral en juicio. Recuérdese la patética realidad de nuestro presente y reciente pasado sobre la oralidad de nuestras audiencias penales: "...Reducido en el último decenio a una a tarea de indignidad, de fatigoso dictado, de dispendiosas transcripciones, donde resaltan las incoherencias, fruto de la lentitud escritural, la incomodidad de los pocos asistentes y la desesperación del ccusado, que siente que esta es otra para maltratarlo y disminuirlo en su capacidad defensiva. La audiencia pública es una acto caricaturesco que tiene por escenario una abarrotada secretaría, limitado a la desapacible lectura de memoriales o a la deprimente tarea de dictar a unos subalternos sin vocación de servicio ni sentido de pertenencia, dominados por la apatía y la dejadez"3.

\section{Principio de inmediación}

Exige la presencia y contacto directo del juez con el debate probatorio y argumentativo de los adversarios: Garantiza que la valoración probatoria se ajuste a lo realmente vertido en juicio y no a aquello que el frío y rígido papel desdibuja por la intervención de muchas manos en el proceso de recolección de la prueba.

Se halla hermanado el principio de inmediación con el de concentración de la prueba, que indica que todas las pruebas deben practicarse y controvertirse en juicio (en audiencia).

"La inmediación, junto a la publicidad y a la oralidad, supone el desarrollo directo de las pruebas ante los jueces de la audiencia, quienes percibirán lo que ya otros ojos y oídos no podrán ver ni oír. El juez-persona asume, valora, aprecia y considera lo actuado, pero lo actuado ante él. Y esa asunción de datos, de pruebas directas $o$ indicios, exige examinar la mente de quien depone, de quien explica, de quien razona, porque ese juez-persona tendrá que valorar anímicamente el

${ }^{2}$ Bazzani, Montoya Darío en "Derecho Penal y Sistema Acusatorion. Compilado por Antonio José Cancino. U. Externado de Colombia. Oct. 2003. Pág. 302.

${ }^{3}$ Fernández León, Whanda. "Sistemas Penales de Juzgamientos." Ediciones Librería el Profesional. Primera Edición. 2001. Pág. 122. 
pensamiento de quien ante su presencia se está manifestando en libertad. El querer, la intención o el deseo de quien habla, está escondido en lo más profundo de su mente, de su conciencia, en el arcano espíritu de su yo. El juez debe apreciar in situ, la veracidad y la certeza. Lo que otros ojos y oúdos no pueden ver ni oúr" (Sala segunda del Tribunal Supremo de España. "Proceso penal y derechos fundamentales, desde la perspectiva jurisprudencial". Editorial Colez, 1994).

\section{Principio de imparcialidad}

Desborda el contenido del mencionado principio, la mera referencia a la necesidad de que el juzgador dirija el juicio y profiera el fallo haciendo respetar su autonomía y consultando la constitución y la ley. En un sistema acusatorio, además la imparcialtdad del juez se traduce en su inmaculada concepción, que llegue al debate descontaminado y se mantenga alejado de la tentación de formular o pensar siquiera en hipótesis sobre los hechos juzgados. "...La concreción de la imparcialidad del juez en el sistema acusatorio, se ve reflejada en que en su actitud de director del debate sólo es un observador pasivo sin facultades oficiosas o discrecionales; no decreta pruebas porque debe respetar el querer de las partes, no interroga testigos ni peritos porque debe dejarlo a las partes.... ${ }^{5}$.
- Principio de continuidad y fallo inmediato.

Ligados a los principios ya reseñados, el de continuidad implica que la controversia debe tramitarse en audiencias continuas sin que se mezcle en su desarrollo debate y asunto diverso (otro juicio). El fallo debe anunciarse tan pronto se presenten pruebas y alegaciones.

\section{La estructura de la actuación penal}

El Acto Legislativo 03 "de 2002 y el proyecto de ley presentado por la Comisión Constitucional Redactora que en este momento se debate en el Congreso, consagran la existencia de dos grandes fases: una, la de investigación y otra, la de juzgamiento.

\section{Fase de investigación}

Es conocida como la fase preparatoria para el juicio y tiene por objeto preparar y asegurar los medios y órganos de prueba, estructurar la acusación fáctica y jurídica. Su dirección estará a cargo de la Fiscalía General de la Nación.

Contiene una sub-etapa de indagación y otra de investigación propiamente dicha. La primera corresponde a la policía judicial (bajo control jurídico de la Fiscalía, art. 194) y la segunda a la Fiscalía.

La indagación se desarrolla temporalmente entre la ejecución de

\footnotetext{
${ }^{4}$ Reproducido por Fernández León, Whanda. "Obra Cit». Pág. 102.

${ }^{5}$ Defensoría del Pueblo. Dirección Nacional de Defensoría Pública. Unidad de Capacitación, modulo II. "Axiología y Deontología del Procedimiento Penal y precedente judicial".
} 
la conducta punible y la formalización de la imputación.

La sub-etapa de investigación comprende desde el momento de la formalización de la imputación hasta el momento en que se presenta el escrito de acusación.

Las disposiciones normativas que regulan el desarrollo de esta fase se hallan formalmente ubicadas en lo títulos I (la indagación y la investigación) y II (medios cognoscitivos en la indagación y la investigación) del libro II denominado Técnicas de indagación e investigación de la prueba y sistema probatorio.

Debo insistir que durante la fase investigativa, la labor se debe concentrar en planear el trabajo que permita consolidar una acusación y llevar con éxito el debate probatorio y argumentativo que permita persuadir al fallador, que su feoría del caso es la correcta (tema sobre el que trataremos adelante).-

Ilustrativo para describir el propósito de dicha etapa y la forma más adecuada de adelantarla resulta transcribir el artículo 201 del proyecto de Código de Procedimiento Penal:

"Programa metodológico: Recibido el informe de que trata el artículo 199, el fiscal encargado de coordinar la investigación dispondrá, si fuere el caso, la ratificación de los actos de investigación y la realización de reunión de trabajo con los miembros de la policía judicial, si la complejidad del asunto lo amerita, el fiscal dispondrá, previa autorización de la unidad a que se encuentra adscrito la ampliación del equipo investigativo.

Durante la sesión de trabajo, el fiscal, con el apoyo de los integrantes de la policía judicial, se trazará un programa metodológico de la investigación, el cual deberá contener la determinación de los objetivos en relación con la naturaleza de la hipótesis delictiva; los criterios para evaluar la información; la delimitación funcional de las tareas que se deban adelantar en procura de los objetivos trazados; los procedimientos de control en el desarrollo de las labores y los recursos de mejoramiento de los resultados obtenidos.

En desarrollo del programa metodológico de la investigación, el fiscal ordenará la realización de todas las actividades que no impliquen restricción a los derechos fundamentales y que sean conducentes al esclarecimiento de los hechos al descubrimiento de los elementos materiales probatorios, a la individualización de los autores $y$ participes del delito, a la evaluación y cuantificación de los daños causados y a la asistencia y protección de las víctimas.

Los actos de investigación y estudio y análisis de laboratorio serán ejercidos directamente por la policía judicial..

En síntesis, propone (o tal vez exige) la norma una formula metodológica organizativa de la labor investigativa que se traduce de manera sencilla: trabajo en equipo. Atrás quedarán las extensas jornadas de producción de providencias que consumen cerca del $80 \%$ del tiempo de los fiscales para que se concentren en su misión principal: 
la búsqueda y el aseguramiento de la prueba.

Como dato final conviene precisar que en dicha fase interviene el juez que ejerza la función de control de garantías, básicamente cuando sea requerido por la Fiscalía para autorizar restricciones a derechos fundamentales (control previo) o para validar actuaciones (no decisiones) del ente investigador en los casos excepcionales en que estos estén facultados para limitar derechos (control posterior).

\section{Fase de juicio}

El juicio inicia con la presentación, por parte del fiscal, del escrito de acusación ante el juez competente. Continúa con la audiencia de formulación de acusación, la audiencia preparatoria, la audiencia de juicio oral (se anuncia el sentido del fallo) y termina con la audiencia de proferimientó de la sentencia.

Pieza medular de esta fase 10 constituye el desarrollo del juicio oral: "Es la fase procesal propiamente dicha".
Es la etapa central del procedimiento penal acusatorio. En ella se realizan una o más audiencias continuas y públicas, en las cuales de manera oral, el fiscal sustenta su acusación, la defensa su exculpación y el juez decide sobre los elementos probatorios presentados y controvertidos en la audiencia por las partes.

Se inicia con los argumentos de apertura de cada parte, donde ellas hacen una exposición breve de su teoría del caso para que el juez tenga una visión de lo que se prosentará en el juicio, la hipótesis fáctica, la adecuación jurídica y la prueba que se hará valer en el juicio. Continúa con la actividad probatoria contradictoria, donde las partes interrogan y contrainterrogan testigos $y$ peritos, introducen evidencias físicas o materiales y las analizan. Termina con los alegatos de conclusión donde las partes argumentan sus pretensiones $y$ dan sugerencias al juez sobre la valoración de las pruebas. Allí el juez emite su fallo y luego en otra audiencia dicta su sentencia " ${ }^{6}$.

6 Jiménez M. Fernando. "Estructura Penal Acusatoria en la Reforma Constitucional de 2002". Contenida en la Revista el Debate Oral. Ed. No. 4. (Oct. De 2003) publicación de la Comisión Interinstitucional para la implementación del Sistema Acusatorio. 


\section{Estructura gráfica del proceso penal ${ }^{7}$}

Estructura de la actuación penal

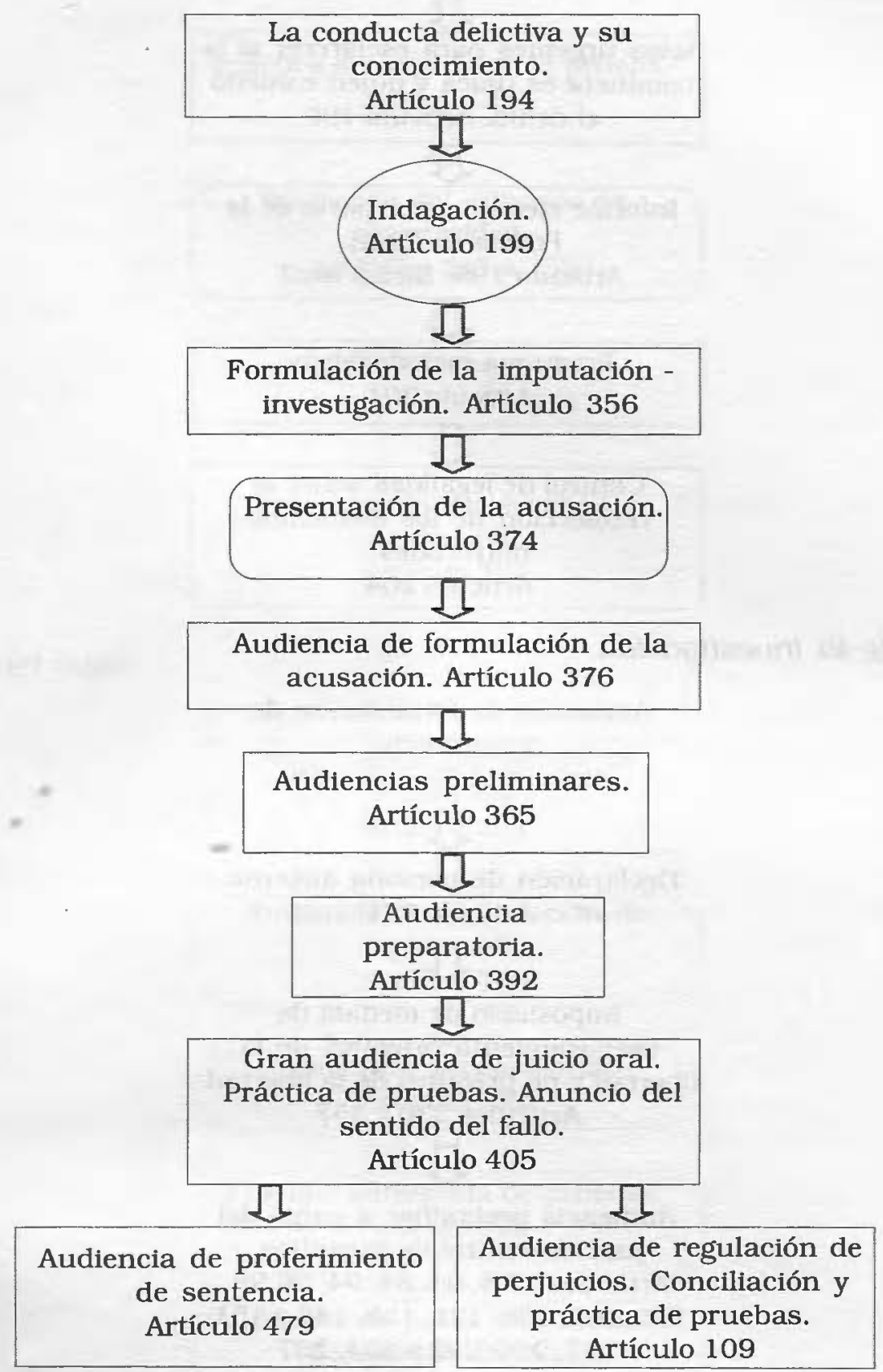

${ }^{7}$ Tomado de Jaramillo Diaz Juan Guillermo. Obra Citada. Pág. 109 a 113. 
Estructura de la indagación

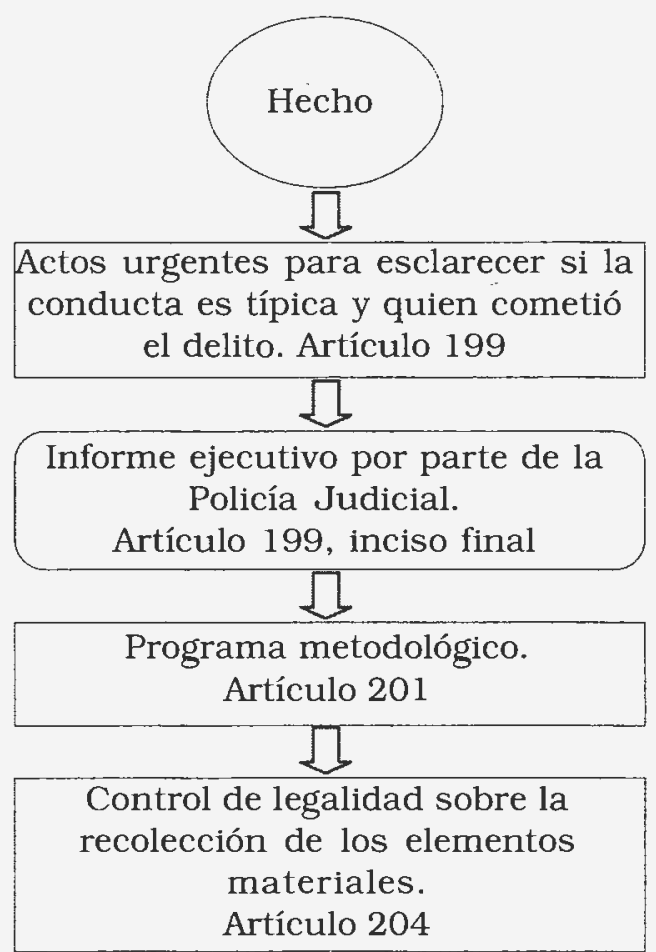

Estructura de la investigación

Audiencia de formulación de imputación.

Artículos 292, 356, 358

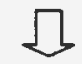

Declaración de persona ausente.

Artículo 131

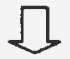

Imposición de medida de aseguramiento privativa de la libertad y no privativa de la libertad. Artículos 330 y 357<smiles>c1ccc2ccccc2c1</smiles>

Audiencia preliminar a cargo del juez de control de garantías.

Artículos 37.5, 91. 84, 94, 96,98, $104,105,108,131,135,148$ a 151 , $167,230,232$ a 234,237<smiles>C1=CC2CCC=C1C2</smiles>

Negociaciones y pre acuerdos.

Artículos 386 a 391<smiles>C1CCCC1</smiles>

Cadena de custodia.

Artículo 259 a 276 


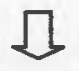

Ubicación de los elementos materiales probatorios y medios cognoscitivos.

Artículo 199 a 258<smiles>C1CC2CC1C2</smiles>

Práctica anticipada de la prueba. Artículo 299<smiles>C1CC2CC1C2</smiles>

Aplicación del principio de oportunidad.

Artículos 347 a 355<smiles>C1CC2CC1C2</smiles>

Solicitud de preclusión.

Artículos 369 a 373<smiles>C1CCCC1</smiles>

Presentación del escrito de acusación.

Artículo 374

\section{Estructura del juicio}

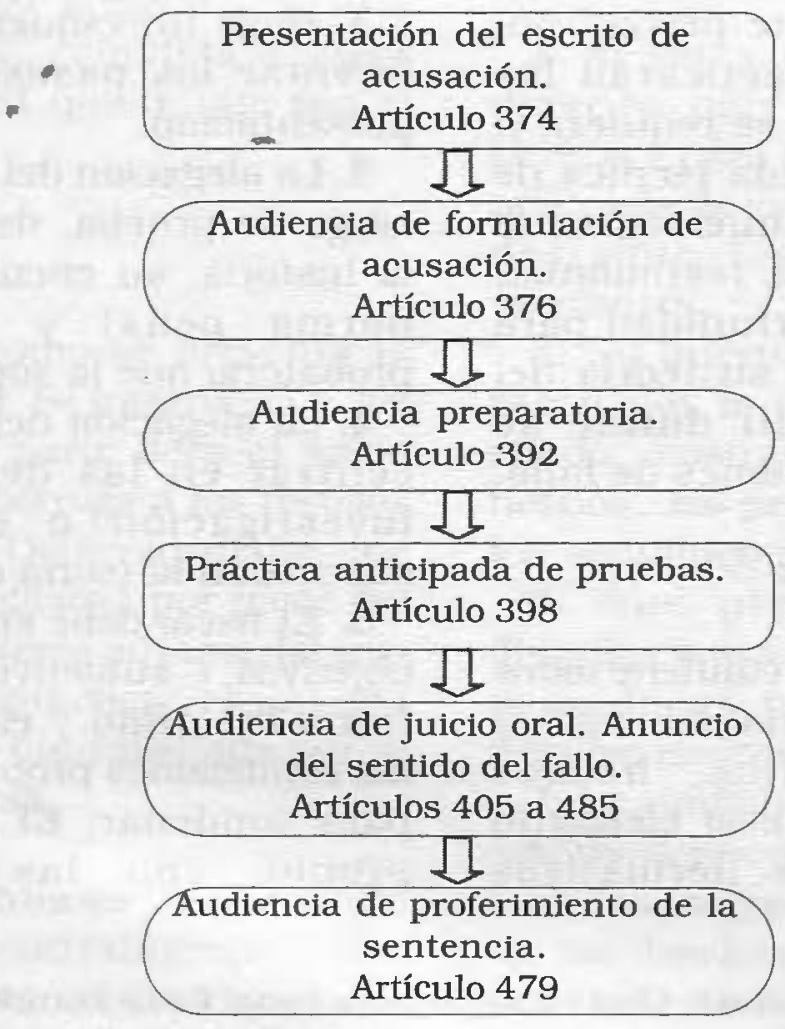




\section{Teoría del caso $^{8}$}

Para afrontar un litigio judicial tanto la Fiscalía como la Defensa deben diseñar su teoría del caso desde el primer momento que obtengan la información sobre los hechos.

$\rightarrow+$

La teoría del caso sirve para planear la actuación del proceso, verificar el desempeño durante el debate oral y concluir adecuadamente durante el debate de cierre.

Corresponde a cada parte persuadir al fallador que su teoría es la correcta y la del adversario es equivocada, para ello contarán en el juicio oral con las siguientes oportunidades: 1) el alegato de apertura, en el cual las partes expondrán brevemente su teoría y relacionarán las pruebas que la soportarán; 2) el debate probatorio, fase en ła cual se practicarán las pruebas y para la cuâl se requiere el manejo de una adecuada técnica de interrogatorio y contrainterrogatorio para encarar la prueba testimonial; 3 ) el alegato final, oportunidad para convencer al juez que su teoría del casó se probó es allí donde se expresarán las pretensiones de fallo.

\section{Alegato de apertura}

El alegato de apertura contiene todos los elementos de la teoría del caso: el elemento fáctico (los hechos penalmente relevantes); el elemento jurídico (fundamentos normativos doctrinales y jurisprudenciales) y el elemento probatorio (la relación de pruebas que desfilarán en el juicio).

Es la primera oportunidad que tienen las partes para adelantar el proceso de persuasión al juez. Se habla en tiempo futuro, se anuncia lo que verá el juez, porque las pruebas no se han practicado aún: "Señor juez en el día de hoy le demostraré..., le probaré...quedará usted convencido que mi teoría es sólida y consistente porque...".

$>$ Recomendaciones:

1. Antes que presentaciones distractoras y llenas de contenido abstracto o doctrinal, es conveniente que desde el comienzo se envíe al juez el mensaje claro del tema sobre el que versa su teoría del caso.

2. Haga un esquema bosquejo para orientar los pasos que dará en la presentación.

3. La alegación del fiscal, que lleva la carga de prueba, debe enunciar toda la historia, su encuadramiento en la norma penal y cada elemento probatorio que la soportará.

4. La alegación del defensor se debe centrar en las deficiencias de la investigación o en hechos que desvirtúan la teoría de la Fiscalía.

5. El fiscal debe enunciar los juicios objetivos y subjetivos que dispone la teoría del delito y el cumplimiento de las condiciones probatorias necesarias para condenar. El defensor hará lo propio, con las eximentes de

8 Tomado de "Técnicas del Juicio Oral en el Sistema Penal Colombiano». Libro del Discente. Material elaborado por el Programa para una cultura de la oralidad desde la Universidad Colombiana. 
responsabilidad o con la enunciación de la falta de requisitos para que configuren los supuestos de la acusación y por lo tanto de la sentencia.

6. Todo lo que se enuncie pruébelo. Las promesas incumplidas son tomadas por el contradictor para atacar su caso durante el período probatorio y sobretodo, en el alegato de conclusión. Nunca dé opiniones personales.

7. Su presentación debe ser completa y eficiente. Utilice ayudas audiovisuales para recrear los hechos y garantizar un mejor nivel de persuasión.

8. Escuche atentamente el alegato de apertura de la contraparte, para descubrir promesas no cumplidas y debilidades probatorias.

9. Háblele al juez en voz alta, clara y segura, haciendo contacto visual con él mientras le habla.

10. Concluya su alegato con una petición concreta, completa y clara sobre lo que usted quiere que sea el fallo del juez.

\section{Interrogatorio}

Es la manera como se presenta la prueba testimonial. Se interrogan a los testigos que cada parte lleva al juicio oral y se contra interroga a los testigos de la contra parte. Debe recordarse que no existe prueba oficiosa por parte del juez. Por ser un sistema adversarial solo se ordena para ser practicada la prueba testimonial pertinente solicitada por la Fiscalía y la Defensa.

Utilizar una buena técnica de interrogatorio y contrainterrogatorio conduce a presentar el testimonio de una manera lógica, efectiva $y$ persuasiva, facilitando con ello probar su teoría del caso.

\section{$>$ Recomendaciones}

1. En su estrategia probatoria testimonial nunca debe faltar una estructura de prelación u ordenación en la presentación de sus testigos. Antes de preparar a un testigo para el juicio usted debe preguntarse ¿qué le aporta a mi teoría del caso? y ¿cuáles son los temas que debe probar con el testigo?.

2. Antes de proceder al interrogatorio debe conocer bien al testigo en sus condiciones personales, familiares y sociales. Debe saber cuáles son sus fortalezas y debilidades y cómo afrontar éstas.

3. Al testigo debe ilustrarlo, no para que falte a la verdad o para que engañe al juez, por el contrario, para resaltar la veracidad y la efectividad de su testimonio.

4. Al testigo debe ilustrarlo para que describa muy bien la escena de los hechos y para que haga una secuencia ordenada de los mismos, buscando que destaque los temas probatorios relevantes.

5. Su interrogatorio debe develar la razón por la cual el testigo ha sido citado, mostrando su relación con los hechos, los personajes, los lugares y los sentimientos.

6. Sus preguntas deben estar dirigidas a que el testigo dé una visión panorámica para luego caer en los detalles trascendentales de los hechos.

7. La confiabilidad y veracidad de su testigo depende de la forma como le haga las preguntas sobre la descripción de los hechos. Debe ser preciso y detenerse en los temas esenciales que quiere enfatizar. 


\section{No pierda el rumbo del interrogatorio} y utilice bien el tiempo que tiene para él, evitando desconcentrar o desinteresar al juez.

9. Inicie y termine su interrogatorio con frảsés $u$ oraciones fuertes que se fijen en la mente del juzgador, usando lenguaje verbal y no verbal apropiado y permitiendo al testigo explicar su dicho.

10. Haga preguntas abiertas, cerradas, narrativas y de seguimiento. Recuerde que cada pregunta y su respuesta implica efectos positivos o negativos sobre el juez y su valoración del testimonio.

\section{El contrainterrogatorio}

Se contrainterroga a los testigos contrarios. Un buen contrainterrogatorio persigue atacar la credibilidad personal del testigo, atacar la credibilidad del testimonio, obtener que el testimonio apoye así seá parcialmente la teoría del caso del contrainterrogador y sacar a relucir lo que el testigo no dijo cuando fue inicialmente interrogado por la parte que lo citó.

Es importante recalcar que a diferencia del interrogatorio, el contrainterrogatorio permite las preguntas sugestivas. A continuación, presento el siguiente ejemplo que ilustra la utilización de este tipo de preguntas por parte del defensor y en general la técnica del contrainterrogatorio ${ }^{9}$ :

P: Señora Kiev, usted declaró en el examen directo que su marido había abusado de su hija en varias ocasiones, ¿no es así?
R: Así es.

P: ¿Y eso la impactó mucho?

R: Por supuesto... ¡cómo no me iba a impactar!

P: Bien... ¿Encaró a su marido con lo que Ana le había contado?

R: No.

P: ¿Le hizo saber de alguna manera qué usted sabía lo que estaba ocurriendo?

R: No.

P: Señora Kiev, ¿Cuántas veces recuerda que Ana le haya dicho, durante 1992, lo qué su padre le hacía?

R: No sé...tres... Quizás cuatro.

P: En tres, quizás cuatro oportunidades, su hija de 12 años le dice que está şiendo abusada sexualmente por su padre $\vec{y} \not$ ¿usted no hizo nada?

R: No.

P: ¿No llamó a la policía?

R: No.

P: ¿No pidió ayuda a nadie?

R: Estaba recién llegada...no dominaba bien el idioma...no sabía a quién recurrir.

P: Hablando de eso, usted abrió una cuenta corriente en el Banco Americano hacia finales del año 1991 ¿no es verdad?

R: Sí, creo que fue alrededor de esa época.

P: Y seguramente no supo bien al principio en qué banco le convenía abrirla ¿no es así?

R: Bueno, pregunté en un par de lugares...

P: De manera que fue a un par de bancos antes de decidirse por el Banco Americano ¿es eso correcto?

R: Sí.

P: Y los ejecutivos que la informaron no hablaban polaco ¿no es así?

R: No, no hablaban polaco.

P: ¿Hablaban castellano?

R: Sí.

P: ¿Igual qué el ejecutivo que finalmente tramitó su cuenta en el Banco Americano?

R: Sí.

P: Y usted hizo todo ese proceso sola ¿no es verdad?

R: Bien, a veces me acompañaba mi marido.

9 Tomado de "Técnicas del jutcio Oral en el sistema Penal Colombiano - Lecturas Complementarias». Material elaborado por el Programa para una cultura de la oralidad desde la Universidad Colombiana. 
P: ¿Pero muchas veces no?

R: Ásí es, muchas veces no.

P: ¿Muchas veces tuvo que lidiar sola con ejecutivos que le pedían documentos y datos sobre su persona?

R: Sí.

P: ¿Y al parecer se pudo entender con ellos, pues le abrieron la cuenta?

R: Sí supongo.

P: ¿Pero seis meses después, hablando mejor el idioma, no fue capaz de llamar a la policía, ni a un hospital, ni al centro comunitario de su municipalidad cuando supuestamente Ana le dijo por primera vez que estaba siendo abusada por su padre?

R: Es que usted tiene que entender...

P: Señora, estoy tratando de entender, así que le ruego que responda mi pregunta; contactó a alguna persona para que la adara con el hecho de que, según Ana, su dre estaba abusando de ella?

R: No.

P. Pasando a otra cosa, señora Kiev ¿cuántas teces tomaron vacaciones usted y su marido en 1992?

R: No lo sé...creo que dos veces.

P: Y podría decirle al Tribunal ¿dónde fueron y aproximadamente en qué fechas?

R: Bien, déjemie pensar...la primera vez salimos en junio, arrendamos una auto y fuimos al norte. La segunda vez en octubre, viajamos a Buenos Aires.

P: Señora Kiev, no la escuché; usted dijo en el examen directo que su marido la invitó a un crucero por el Caribe en mayo. ¿Es cierto?

R: Cierto,-fueron tres veces entonces las que salimos.

P: Y me parece haberle oído decir que era... ¿cuál fue la expresión que utilizó?...su «segunda luna de miel»

R: Sí, dije eso.

P: ¿Podría explicarnos a qué se refería?

R: Bueno, hacia tiempo que no podíamos tomarnos vacaciones $\mathrm{e}$ iban a ser las primeras en nuestro nuevo país, además cumplíamos ese mes veinte años de casados...

P: ¿Era, pues, una situación romántica?
R:Sí, supongo que podría decirse de ese modo.

P: ¿Y cómo estuvieron las relaciones con su esposo en ese viaje?

R: Fantásticas.

P: Déjeme ver si entiendo lo que me dice... su hija de 12 años le confiesa que su padre está abusando de ella... y un mes después ¿usted sale con su abusador a una romántica «segunda luna de miel»?

R: Yo quería proteger a mi hija...

P: Ya veo... y luego mientras la situación en su hogar se ponía todo lo tensa que usted nos ha referido, ¿se tomó otras dos vacaciones con su marido?

R: Sí.

P: Que estaba abusando de su hija...

R: Bueno... sí, quizás no debí hacerlo...

P: Yendo a otra cosa, usted nos dijo en el examen directo que había traído a su madre desde Polonia para que protegiera a Ana ¿es eso correcto?

R: Sí, así es.

P: ¿De qué manera se supone que debía ella protegerla?

R: Bueno la idea era que Ana no estuviera en la casa sola con su padre mientras yo hacía mi turno en el negocio.

P: La protección consistía, pues, en que su madre estuviera con Ana en la casa cuando usted no estuviera ¿cierto?

R: Sí.

P: Sin embargo, a poco andar su madre comenzó también a trabajar en el negocio ¿no es verdad?

R: Sí. Nos estaba yendo muy bien y yo sola no podía con todo el negocio.

P: Así que le pidió a su madre que la ayudara ¿no es verdad?

R: Sí.

P: Que compartiera el turno con usted, ¿no es cierto?

R: Sí

P: Y su madre no puede estar en dos lugares a la vez... ¿me equivoco?

Fiscal: Objeción.

Defensa: Retiro la pregunta, su señoría. No tengo más preguntas. 


\section{Recomendaciones}

1. Pregúntese primero sí es conveniente realizar el contrainterrogatorio, analizando si el testimonio afecta su teoría del caso, si se trata de un testigo importante o si es un testigo creíble.

2. Una vez que tenga claro el propósito o propósitos del contrainterrogatorio, establezca lo que quiere que se revele de ese testigo o del testimonio. Establecido lo que quiere revelar seleccione los temas del contrainterrogatorio.

3. Al planear el contrainterrogatorio piense cómo encaja ẹl testigo en la teoría del caso del sujeto procesal contrario (acusación o defensa) y cómo afecta la propia teoría del caso.

4. Inicie el contrainterrogatorio buscando sacar del testigo cualquier testimonio que pueda favorecer su posición, es decir, la que pueda apoyar su teoría.

5. Siga con cualquier información que pueda desacreditar al testimonio, por ejemplo, contradicciones o condiciones que podrían hacer imposible la observación.

6. Termine con factores personales que puedan desacreditar o poner en duda al testigo, como parentesco, relación laboral con el imputado o la defensa, o cualquier otra parte interesada, etc.

7. Utilice apoyos audiovisuales para ayudar a los jueces a visualizar el incidente, para señalar áreas problema en el testimonio del testigo, para obtener reconocimientos o atacar la credibilidad del testimonio.

8. Demuestre al testigo que usted tiene algún conocimiento sobre los hechos y que sabrá si él se desvía de la verdad.
9. Repita la pregunta que no respondió el testigo para obtener la respuesta que desea y para afectar su credibilidad. Mencione este hecho en su discusión final.

10. Haga preguntas al perito para determinar aspectos tales como: características de sus honorarios, su área y tiempo de experiencia, los fundamentos de su opinión, términos sencillos para conceptos complejos, idoneidad para un trabajo cuidadoso y detallado, hechos no confiables en su boca, etc.

\section{Alegato final}

Una vez concluido el debate probatorio, las partes deben sintetizar lo ventilado en juicio con el propósito de convencer al juez que su teoría del caso fue probada y que la de la contraparte no logró su cometido. Es la última oportunidad que tienen de comunicarse con el juez. Después de ello vendrá el anuncio del fallo.

\section{$>$ Recomendaciones}

1. El mensaje final debe se completo y conciso sobre el tema del debate: los hechos, las pruebas y los fundamentos jurídicos. Concéntrese en el tema, en los puntos relevantes que ha logrado y en la conclusión.

2. La fuerza de sus argumentos jurídicos, la forma como lo presente, el lenguaje que use y su estilo de comunicación, son muy importantes para lograr la atención del juez y para persuadirlo.

3. Su mensaje debe ser oportuno y no extenso. Controle su tiempo y sepa cómo abordará cada tema. Evite la información superflua. 
4. Escoja una y otra vez los temas que abordará en su alegato y los calificativos para tratar a los testigos y al acusado. Complemente su mensaje persuasivo con apreciaciones y calificativos de todo orden.

5. Use preguntas retóricas para precisar la controversia, para retar a la contraparte y establecer claramente puntos a favor.

6. Apóyese en el conocimiento cotidiano ciudadano y en la experiencia diaria para fortalecer, o atacar la conducta o los hechos planteados.

7. Examine el peso que los puntos problemáticos tengan en la teoría del caso. Si no son lo suficientemente relevantes, no se desgaste. Si lo son, dé una explicación razonable y una valoración para el juez.

8. Aproveche los hechos que no le ha controvertido su contraparte. Es un buen respaldo para interpretarlos a favor, sumándolos al alegato.

9. Realice concesiones favorables al oponente que no sean nocivas a su teoría del caso. Esto da muestras de cierta objetividad en los planteamientos y convencimiento frente a su argumento adversarial.

10. Termine en un punto alto que concentre la atención del juez frente a la síntesis del alegato.

\section{Las objeciones}

Las objeciones facilitan el ejercicio del derecho de contradicción y tienen por finalidad que las partes puedan controlar el cumplimiento de las reglas ético-jurídicas del debate.
Se pueden objetar pruebas (en la audiencia preparatoria o en el juicio oral cuando se solicita por considerarse sobreviviente), preguntas, respuestas y alegatos.

Se objetan pruebas por inconducentes, ilegales, legalmente prohibidas o manifiestamente superfluas.

Se objetan preguntas capciosas, irrelevante o inconducente, sugestiva (en el interrogatorio), conclusiva, que solicita opinión a un testigo no calificado, confusa o ambigua, especulativa, argumentativa, compuestá, repetida y tendenciosa.

Se objetan respuestas sobre preguntas ya contestadas y viceversa, se objeta cuando el testigo se niega a dar respuesta a la pregunta.

Se objetan alegatos así. E1 de apertura cuando en lugar de anunciar la prueba que presentará, formula un argumento sobre la misma. El de conclusión cuando se alega o argumenta sobre un hecho que no fue probado, cuando se realiza una cita jurisprudencial equivocada, falsa o fuera de contexto o cuando se distorsiona lo establecido en las pruebas cambiando su contenido.

\section{$>$ Recomendaciones}

1. En la audiencia preparatoria realice objeciones a las pruebas para que no ingresen al juicio oral las inconducentes, ilegales, prohibidas, ineficaces o superfluas. 
2. En la práctica de pruebas, en el interrogatorio y contrainterrogatorio, objete las preguntas que son formuladas indebidamente o tienden a distorsionar el sentido de la prueba.

3. Objete las respuestas cuando fueron dadas con anterioridad y se están repitiendo, o cuando no se quieren dar.

4. En los alegatos de apertura y conclusión objete para evitar comportamientos indebidos.

5. Tenga cuidado, entre más objeciones haga, se tendrá la sensación que usted no tiene un caso sólido y por lo tanto recurre a maniobras para interrumpir a sus opositores (no abuse de las objeciones).

6. Lo primero que debe pensar al objetar, es cuán necesaria o relevante frente a la teoría del caso es la objeción y qué se obtendrá con ella.

7. Concéntrese en el interrogatorio, pensando en objeciones que pueda hacer.

8. Para que la objeción sea efectiva, realícela antes que se termine de preguntar, contestar o argumentar. Una pregunta ya contestada es un hecho ya declarado que no se puede borrar de la mente del juzgador.

9. El fundamento de la objeción debe darse de manera clara y rápida. No se necesita más, ya que el juez está atento y conoce el alcance de cada objeción.

10. Para objetar hay que hacerlo con contundencia y con tono de voz fuerte, para ser escuchado por el juez. La objeción hay que dirigirla al juez, no al abogado que está interrogando, contrainterrogando o alegando, ni al testigo que está respondiendo.

IV. Retos y desafíos para la enseñanza del nuevo sistema penal

\section{Capacitación judicial}

Desde el año 2002 se acordó integrar la comisión interinstitucional para el impulso de la oralidad en el proceso penal conformada por los más altos dignatarios de las entidades comprometidas y protagonistas de la justicia penal (Consejo Superior de la Judicatura, sala Penal de la Corte Suprema de Justicia, Fiscalía General de la Nación, Procuraduría General de la Nación y Defensoría del Pueblo). No debe desconocerse que previamente ya se habían desarrollado algunas propuestas de capacitación en juicio oral para ser aplicadas con el actual sistema $^{10}$.

Es por ello, que una vez aprobado el acto legislativo 03 de 2002 y a la par con el trabajo de redacción de los proyectos de ley pertinentes para adoptar el nuevo sistema penal que estuvo a cargo de la Comisión Constitucional creada para tal efecto, la comisión para el impulso de la oralidad, se ha puesto a la tarea de diseñar un Plan Nacional de Formadores para los funcionarios de la Rama Judicial, Fiscalía, Procuraduría y Defensoría del Pueblo.

E1 plan busca desarrollar en los operadores de justicia habilidades y

${ }^{10}$ Ver referencias en Ramírez Bastidas, Yesid. "El juicio oral en Colombia». (Capitulo III. Capacitación interinstitucional). Ediciones Jurídicas Gustavo Ibáñez. 2001. 
destrezas para ser más efectivos en el ejercicio de su nuevo rol y concretar la transformación cultural que exige el sistema penal futuro.

Se dispuso como contenido curricular del plan:

$>$ ÁREAS TEMÁTICAS EN LA FASE DE LA INVESTIGACIÓN

1. Tema y teoría del caso.

2. Preparación para el juicio.

3. Direccionamiento estratégico de los medios de prueba.

4. La negociación como forma alterna de solución de conflictos.

> ÁREAS TEMÁTICAS EN LA FASE DEL JUICIO

1. Razonamiento oral para la apertura del juicio.

2. Interrogatorio.

3. Contrainterrogatorio.

4. Objeciones.

5.Argumentos orales persuasivos para la clausura del juicio.

6. Dirección y control del juicio oral.

7. Debate de la prueba judicial.

> TEMÁTICAS TRANSVERSALES

1. Técnicas para la comunicación oral.

2. Modelo de gestión de oralidad.

$>$ TEMÁTICAS DE CONTEXTUALIZACIÓN

1. Sensibilización al cambio.

2. Principios y valores.

3. Estructura del sistema acusatorio.

4. Marco jurídico de la oralidad en el proceso penal colombiano.
5. Desarrollo de la oralidad en la legislación comparada.

El plan ya se empezó a ejecutar y por ello han sido seleccionados, en algunos distritos judiciales, servidores de cada institución comprometida, quienes ya están siendo capacitados y se encargarán de constituir la red de formadores que replicará los conocimientos, habilidades y destrezas adquiridas a sus pares.

2. Programa para una cultura de la oralidad desde la Universidad colombiana

Conscientes que la transformación cultural que se exige para la aplicación del sistema es de largo aliento y que el esfuerzo inicial traducido hasta ahora en capacitar, formar y cambiar la mentalidad de los agentes del sistema, resultaría estéril, si las facultades de derecho del país no se articularan al mismo propósito; es por ello, que surgió de forma paralela el "Programa para una Cultura de la Oralidad desde la Universidad Colombiana".

Entre otras cosas, hay que admitir que los agentes partícipes del actual sistema, por el alto grado de "contaminación" que nos ha aportado el mismo, tienen la doble (y no fácil) tarea de aprender y desaprender; en tanto las futuras generaciones de abogados, que apenas se están formando, tienen la oportunidad perfecta para ser bien preparados desde el hoy para un mañana, en el que pesará menos el hábito propio de la cultura de lo escrito por no 
haberlo adquirido. Su disposición mental no choca con resabios.

El reto lo tenemos las instituciones, docentes y con seguridad no será fácil asumirlo eficientemente, por cuanto somos los primeros en reconocer que es mucho lo que, en primer lugar, debemos desaprender para no "contaminar" a nuestros estudiantes con los ya citados hábitos adquiridos.

En desarrollo del mencionado* programa y con el apoyo del Programa de Fortalecimiento y acceso a la justicia de USAID, en las universidades Nacional, Externado, Santo Tomas, de la Sabana y de Caldas fueron construidas salas de audiencia didácticas para el desarrollo de habilidades y destrezas en oralidad de sus estudiantes de derecho.

Con el mismo propósito, pero destacando que fue con esfuerzo propio, nuestra Universidad Surcolombiana diseñó su Sala de audiencias que ya ha empezado a ser utilizada en las asignaturas de procedimiento penal y asuntos civiles en el proceso penal como espacio para el desarrollo de juicios simulados.

Debemos registrar con complacencia que durante nuestra participación en el Primer Concurso de Oralidad Procesal que se desarrolló en Noviembre de 2003, en la Universidad Santo Tomas de Bogotá, la Universidad Surcolombiana fue invitada a participar activamente en el Programa para una Cultura de la Oralidad desde la Universidad Colombiana y estamos próximos a firmar el acuerdo de cooperación para el desarrollo y promoción de la enseñanza de las técnicas del proceso oral en la cátedra universitaria.

Es por ello, que nos adelantamos a cumplir el compromiso por adquirir, consistente en efectuar reformas curriculares en nuestro plan de estudios que permitan facilitar la enseñanza de las técnicas de juicio oral. En ese sentido se acaba de aprobar la creación de la asignatura "oralidad" ( 2 créditos) para el primer periodo de 2004 .

Igualmente, la cátedra de procedimiento penal, continuará (como se ha venido haciendo desde el segundo periodo de 2003) acercando a sus estudiantes a lo que será el futuro sistema acusatorio, estudiándolo en un capítulo dedicado al acto legislativo 03 de 2002 y los desarrollos legislativos en ciernes.

Importante igualmente resulta destacar el esfuerzo realizado, en desarrollo del programa referido, por el Comité Técnico y Asesor de la Comisión Interinstitucional para el impulso de la Oralidad en el Proceso Penal, al elaborar los manuales didácticos que como parte del acuerdo será suministrado a los profesores universitarios y sus estudiantes; así mismo, existe el compromiso de dotar a las universidades con equipos que le permitirán grabar los ejercicios prácticos y reproducirlos para su crítica y retroalimentación

Los manuales didácticos hasta ahora elaborados con el título común "Técnicas de Juicio Oral en el Sistema Penal Colombiano" son los siguientes: 
$>$ LIBRO DE DISCENTE: Unidades temáticas: Teoría del caso; Técnicas de negociación; Alegatos de apertura; Técnicas de interrogatorio y contrainterrogatorio; Construyendo objeciones; Alegatos de conclusión; La ética en el proceso penal oral.

$>$ LIBRO DEL DOCENTE: Unidades temáticas: Enfoque del aprendizaje; Herramientas metodológicas; Criterios de evaluación de ejercicios prácticos.

- LECTURAS COMPLEMENTARIAS: Unidades temáticas: Elementos de comparación entre los sistemas inquisitivo y acusatorio; Comparativo entre los sistemas acusatorio norteamericano y mixto colombiano; El sistema procesal penal en los Estados Unidos; El sistema penal acusatorio; Acto legislativo No 03 de 2002; La modificación del sistema de juzgamiento e implementación del sistema acusatorio en Colombia; La oralidad, antecédentes en la doctrina y la legislación comparada,-Oralidad en los instrumentos internacionales de Derechos Humanos; Principios que se relacionan con la oralidad; La teoría del caso; La dimensión fáctica del discurso y su evaluación; Entrevista a los testigos; Preparación del testigo; Sintomatología de la mentira; El interrogatorio; $\mathrm{El}$ interrogatorio del testigo desfavorable; Técnica de las objeciones; El contrainterrogatorio y sus objeciones; Objeciones; Aspectos prácticos de la prueba pericial en el debate; Alegatos orales de conclusión; Los alegatos.

Definitivamente insisto en considerar un esfuerzo, la preparación del anterior material habida cuenta de la carencia o insuficiencia de escritos sobre dichos temas en nuestro país, precisamente por la novedad que representan.

\section{Metodología de enseñanza}

La Comisión Interinstitucional para la implementación del sistema acusatorio ha diseñado (junto a las universidades participes del programa) una propuesta metodológica para la enseñanza de las técnicas de juicio oral que me permito transcribir:

"La línea pedagógica que viene trabajándose con las universidades que iniciaron este proceso es la del método empírico-dialéctico, que facilita al alumno comprender la naturaleza práctica del Derecho Procesal y por consiguiente del proceso oral, identificando la relación dialéctica entre el significado de la norma y el hecho concreto al que se ha de aplicar.

El método está definido por el tipo de educación que se pretende brindar, siempre basada en lo prácticoexperimental y en el ejercicio permanente de la contradicción probatoria, fundamento de cualquier sistema acusatorio garantista, efectivo y transparente. No se puede conocer y poner efectivamente en práctica una norma procesal, e inclusive una sustantiva, sin que los operadores conozcan y comprendan su verdadero significado. Podemos decir, que el camino más indicado para conseguir tal propósito, es enfrentar a los estudiantes con los problemas de la vida real través del método de casos.

El método debe facilitar que el estudiante identifique o cree principios 
o conceptos generales a partir de los cuales pueda manejar los hechos concretos que la vida le presentará profesionalmente.

En "el proceso de enseñanza aprendizaje de las técnicas del proceso oral no sólo se deben considerar los contènidos curriculares, sino que las metodologías de enseñanza realmente preparen al estudiante para "El Hacer", que lo enfrenten con la realidad tanto en el aspecto de- las relaciones humanas y sus conflictos, así como con la dinámica del sistema judicial.

Para el uso de casos en la enseñanza activa de las técnicas de oralidad, se recomienda tener en cuenta seis fases o pasos didácticos. En primer término, el profesor da a conocer del alumno los fundamentos teóricos de la técnica que pretende trabajar (la primera siempre será la de construcción de la teoría del caso y su presentación). Luego, le éntrega la información del caso y le solicita que elabore su teoría del caso, según una asignación de roles previa. Seguidamente, el profesor hace una demostración viva de la técnica para que los alumnos observen y den alcance a sus conocimientos teóricos. Después, el alumno hace el ejercicio práctico de la técnica, siendo observado por el profesor y sus compañeros. En seguida, el ejercicio del alumno es objeto de comentarios y críticas constructivas por parte de su profesor. Luego el profesor y el alumno revisan el video y se hacen observaciones más puntuales o personales que involucren estilo. Finalmente, el alumno repite su práctica tratando de corregir los errores manifiestos".

El futuro empezó hoy, nuestra universidad asumirá junto a aquellas que ya iniciaron su camino y con el apoyo de las entidades y agencias involucradas, el rețo de construir los escenarios e imaginarios que faciliten la transformación cultüral requerida para la implementación gradual del sistema acusatorio, la reducción de normales traumatismos y la formación de abogados con compromisos y actitudes éticas en el ejercicio de su profesión.

Por otra parte, confiamos que el estado cumpla su compromiso de disponer los recursos presupuéstales, técnicos y tecnológicos necesarios que exige la implementación del sistema. Recuérdese además que a la par del fortalecimiento de la capacidad investigativa de la Fiscalía General de la Nación se hace indispensable el fortalecimiento de la Defensoría Pública para materializar el principio de igualdad, propio de un sistema adversarial.io 